\title{
Stent-over-sponge (SOS): a rescue option in patients with complex postoperative anastomotic leaks after esophagectomy
}

Anastomotic leak after Ivor Lewis esophagectomy remains a life-threatening complication. Self-expandable metal stents (SEMSs) are one established endoscopic treatment option [1], but endoscopic vacuum therapy (EVT) has become a promising alternative [2]. Currently, there is no conclusive evidence to suggest that one of these options is superior [3]. However, the combination of SEMS with EVT seems to be another suitable therapeutic option for treating complex leaks [4]. The SEMS optimizes the vacuum force by sealing the sponge toward the gastrointestinal lumen and maximizing the suction efficacy ( $\triangleright$ Fig. 1) [5].

We present the case of a 60-year-old man who underwent neoadjuvant chemotherapy followed by Ivor Lewis esophagectomy for adenocarcinoma of the distal esophagus. On the eighth postoperative day the patient showed clinical signs of sepsis and an upper endoscopy showed a semicircular esophagogastric anastomotic dehiscence and a large mediastinal abscess cavity ( $\mathbf{F i g . 2 ,}$ - Video 1).
EVT was performed and a sponge (EsoSPONGE; Aesculap AG, Tuttlingen, Germany) was placed in the abscess cavity. To ensure enteral feeding, a diverted nasogastric tube (Freka Trelumina; Fresenius Kabi, Bad Homburg, Germany) was inserted. The first follow-up endoscopy on Day 4 after initiation of EVT showed an unchanged cavity, so we placed two sponges. The second follow-up endoscopy (Day 7) showed continued poor healing; consequently, we decided to perform stent-over-sponge (SOS) therapy to accelerate the healing process.

At third follow-up endoscopy (Day 15), the sponges and SEMS (Ultraflex; Boston Scientific, Malborough, Massachusetts, USA) were removed. A remarkable improvement in the healing process was observed, with a small, clean, and encapsulated cavity. SOS was terminated and a computed tomography scan the following day confirmed the improvement. A fourth endoscopy (Day 21) showed the small encapsulated cavity, and an additional SEMS was placed to seal the entrance of the cavity. Aspiration pneumonia delayed hospital discharge. At the fifth follow-up endoscopy (Day 46) the
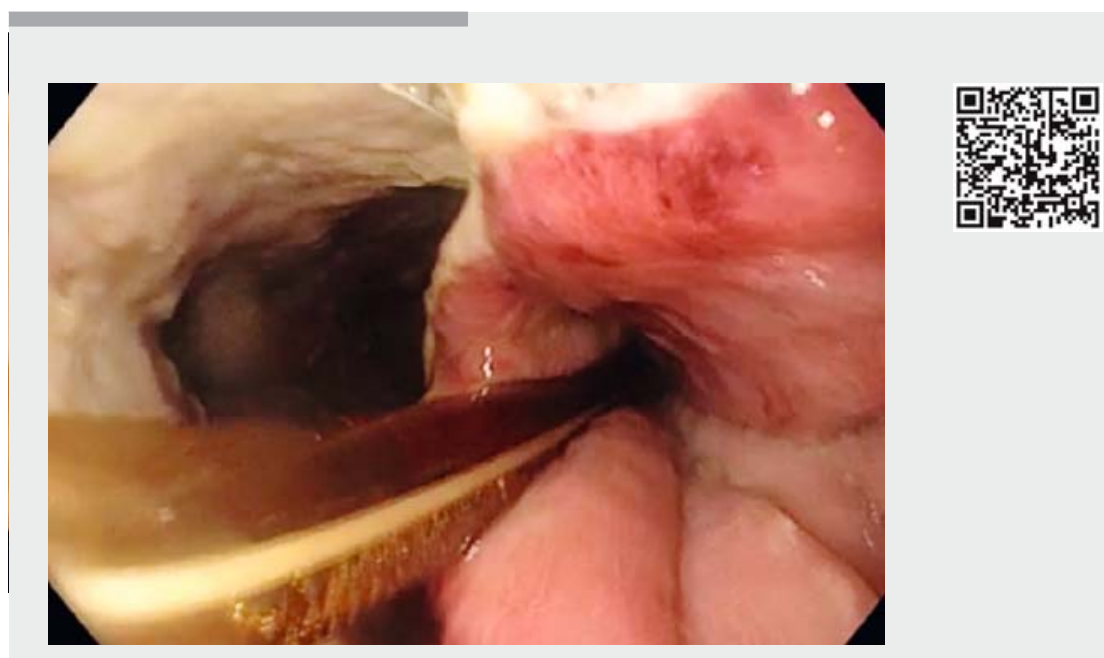

Video 1 The stent-over-sponge rescue method for complex postoperative anastomotic leaks after esophagectomy.

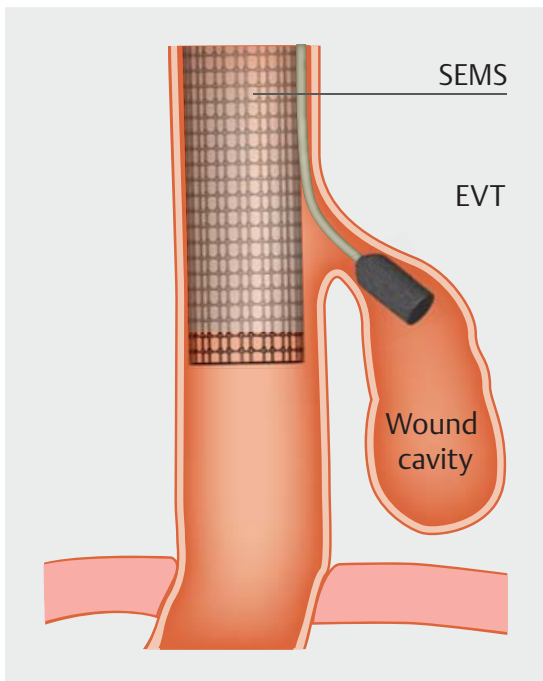

- Fig. 1 Schema of stent-over-sponge method. EVT, endoscopic vacuum therapy; SEMS, self-expandable metal stent.

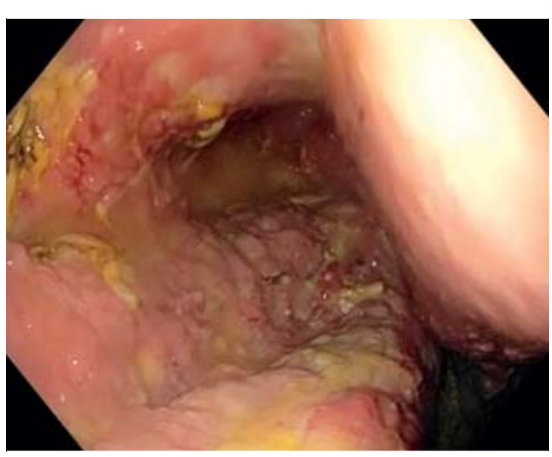

Fig. 2 Complex large cavity in the mediastinum.

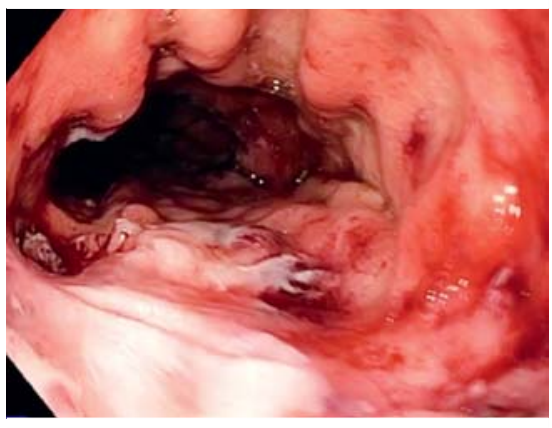

Fig. 3 Sealed leak of the esophagogastric anastomosis. 
SEMs was removed and a completely healed esophagogastric anastomosis was revealed ( $>$ Fig. $\mathbf{3}$ ). The patient was discharged 2 days later.

Endoscopy_UCTN_Code_TTT_1AO_2AI

Competing interests

None

The authors

Isabel Bartella ${ }^{1}$, Christoph Mallmann ${ }^{1}$, Martin Bürger ${ }^{2}$, Ulrich Toex ${ }^{2}$, Tobias Goeser ${ }^{2}$, Christiane Bruns ${ }^{1}$, Seung-Hun Chon ${ }^{1}$

1 Department of General, Visceral and Cancer Surgery, University Hospital of Cologne, Cologne, Germany

2 Department of Gastroenterology and Hepatology, University Hospital of Cologne, Cologne, Germany

\section{Corresponding author}

\section{Seung-Hun Chon, MD}

Department of General, Visceral and Cancer Surgery, University Hospital of Cologne, Kerpener Str. 62, 50937 Cologne, Germany Fax: +49-221-47886227

seung-hun.chon@uk-koeln.de

\section{References}

[1] Plum PS, Herbold T, Berlth F et al. Outcome of self-expanding metal stents in the treatment of anastomotic leaks after Ivor Lewis esophagectomy. World J Surg 2019; 43 : $862-869$

[2] Bludau M, Fuchs HF, Herbold T et al. Results of endoscopic vacuum-assisted closure device for treatment of upper Gl leaks. Surg Endosc 2018; 32: 1906 - 1914

[3] Berlth F, Bludau M, Plum PS et al. Self-expanding metal stent versus endoscopic vacuum therapy on anastomotic leak treatment after oncologic gastroesophageal surgery. J Gastrointest Surg 2019; 23: 67-75

[4] Gubler C, Schneider PM, Bauerfeind P. Complex anastomotic leaks following esophageal resections: the new stent over sponge (SOS) approach. Dis Esophagus 2013; 26: 598 602
[5] Vallo P, Mertens ], Kröger A et al. Stent-oversponge (SOS): a novel technique complementing endosponge therapy for foregut leaks and perforations. Endoscopy 2018; 50: $148-153$

\section{Bibliography}

DOI https://doi.org/10.1055/a-0885-9659

Published online: 2.5.2019

Endoscopy 2019; 51: E227-E228

(c) Georg Thieme Verlag KG

Stuttgart · New York

ISSN 0013-726X

\section{ENDOSCOPY E-VIDEOS}

https:/|eref.thieme.de/e-videos

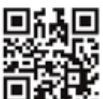

Endoscopy E-Videos is a free access online section, reporting on interesting cases and new

techniques in gastroenterological endoscopy. All papers include a high quality video and all contributions are freely accessible online.

This section has its own submission website at

https://mc.manuscriptcentral.com/e-videos 